that anything can be too small or too trifling to deserve his attention." The modern development of the valve, through the researches of those who have brought it to its present excellence, has rested on a still smaller entity, the electron, a body with a mass of $0^{\circ} 900 \times 10^{-27}$ grams, about $1 / 1800$ of the atom of hydrogen, carrying a negative charge of $\mathrm{I} \cdot 59 \mathrm{I} \times \mathrm{IO}^{-20}$ electro-magnetic units $^{6}$ of electricity, first glimpsed by Crookes, then proved to exist by J. J. Thomson.

The appearance of a Crookes tube or vacuum tube when carrying an electric discharge is well known. When the pressure is sufficiently reduced, the tube is non-luminous except for a beam of light which proceeds normally from the cathode-the negative electrodeand penetrates into the tube a distance depending on the pressure ; this beam constitutes the cathode rays : if the rays strike the glass at the end of the tube, a vivid fluorescence is produced.

Crookes showed that the beam constituted a current of negative electricity; it could be deflected by a magnet. Experiments by Perrin and J. J. Thomson proved conclusively the existence of the negative charge. Thomson showed also that the stream consisted of an assemblage of minute particles-electrons. He measured the velocity of the particles and the ratio $\mathrm{e} / \mathrm{m}$ of the charge on each to its mass. Further experiments, of which perhaps those of Millikan are the most important, have led to a determination of the charge on the electron, and from this and a knowledge of the ratio $\mathrm{e} / \mathrm{m}$ the values of $e$ and $m$ are found. These values are the same whatever be the nature of the cathode from which the rays take their origin-the mass and charge of an electron are the same whatever be its source. Thus now it is scarcely too much to say that nearly all electrical phenomena are conditioned by the presence and motion of electrons. The current in a cable is a stream of electrons; a conductor is a body through which they move freely; an insulator checks their activity. The power that drives our motors comes from them; the light of the electric lamp, the heat that comes from an electric radiator, have their origin in these tiny particles; the plate current of the valve rectifier referred to above is a stream of electrons; when the grid is negatively electrified, it adds negative electrons to the stream; when it is positive, some of the electrons from the filament are stopped in their passage through its interstices to neutralise the positive electricity it possesses.

'Electrical engineering in its many branches is closely bound up with the properties of an electron discovered by men whose sole object it was to advance natural knowledge. Nor is this all : for from the electron

- One electro-magnetic unit is the charge transferred by I ampere circulating for ro seconds. came X-rays, though this, perhaps, is scarcely the correct way of putting it, as J. J. Thomson's discovery really followed that of Röntgen. About I894, physicists in many countries were experimenting with Crookes's cathode rays. A chance observation made by a skilled worker revealed the fact that the cathode rays produced an effect outside the tube in which they were generated. Röntgen in the autumn of $\mathrm{I} 895$ was conducting an investigation with a vacuum tube wrapped in lightproof paper, and noted that a fluorescent screen of barium platino-cyanide lying near shone out when the tube was excited; if he placed opaque objects between the screen and the tube, shadows were cast on the screen, showing that rays, the $\mathrm{X}$-rays, proceeded from the tube in straight lines; and it was quickly found that the rays penetrated substances opaque to light, the penetration depending on the density of the substance. There is no need to dwell on the results that have followed from this and their significance to engineers. X-rays can penetrate 4 to $5 \mathrm{~mm}$. of lead, I $2 \mathrm{~mm}$. of tin, $75 \mathrm{~mm}$. of carbon steel, Ioo to $50 \mathrm{~mm}$. of aluminium, and 300 to $400 \mathrm{~mm}$. of wood. By their aid hidden cracks or faulty welds can be shown upon metal structures, while they have been employed for many industrial purposes, besides their use in surgery and medicine.

For some time the nature of $\mathrm{X}$-rays was a mystery. Their rectilinear propagation and the absence of refraction when they fell obliquely on the surface of a medium other than air were difficult of explanation. Now it is known that they are produced by a very rapid change of motion of electrons. When the velocity of an electron is altered, an electro-magnetic wave is produced, and, starting from the electron, travels outward with the velocity of light. The frequency in this wave-in the number of vibrations per second produced-depends on the suddenness of the change of velocity of the electron. If this is very great, the frequency in the resulting wave is also very great. When a beam of cathode rays falls on the glass walls or on the anti-cathode of an X-ray bulb, the electrons are stopped almost instantaneously. Electro-magnetic rays of very high frequency$\mathrm{X}$-rays-are produced. Their wave-lengths are now known to lie between $12 \times 10^{-8} \mathrm{~cm}$. and $0^{\circ} \mathrm{I} 7 \times 10^{-8}$ $\mathrm{cm}$. The wave-length of visible light is between $7700 \times 10^{-8} \mathrm{~cm}$. and $3600 \times 10^{-8} \mathrm{~cm}$., that of ultraviolet light lies between $3600 \times 10^{-8} \mathrm{~cm}$. and $200 \times 10^{-8}$ $\mathrm{cm}$., and it is to this minuteness of wave-length that the absence of refraction is due. In the hands of Sir William and Prof. W. L. Bragg, it has been the means of revealing the inner structure of materials in a manner which is of the utmost importance to engineers.

\title{
Terrestrial Magnetism and the Orientation Faculty of Birds.
}

THE possible existence of a "magnetic sense" in 1 animals has for long been a subject of speculaion, and Lord Kelvin is numbered among those to whom the idea has proved attractive. No direct svidence in its favour has ever been obtained; but, on the other hand, there is no actual proof that some form of physiological sensibility to the phenomena of terresrial magnetism may not exist and be a factor in that mysterious power of geographical orientation which is displayed by many animals and by primitive man.

The idea has often been invoked in the case of the especially remarkable powers of orientation which are possessed by migratory birds and by homing pigeons, and it is to be feared that much loose talk has at times been indulged in on this particular point. A recent author (F. Cathelin, "Les Migrations des Oiseaux," 
Paris, 1920) has gøne so far as to propound a theory of migration which dispenses with instinctive behaviour in favour of "galvanotropism," and reduces birds to the status of mere automata acting under the compulsion of " des grands courants aériens électro-magnétiques équinoxiaux." Unfortunately for his argument, it is based on a conception of migration which is not consistent with many of the established facts, and it presupposes the existence of physical phenomena as to which the physicists are silent. Nor is its credibility increased by the absence of any suggestion as to a possible physiological mechanism linking the supposed physical causes to the alleged biological effects. At the best it is one of those "explanations" which call for more explaining than the original phenomena.

In these circumstances one welcomes a serious attempt, by a biologist and a physicist in collaboration, to set forth the possibilities of the case. This has been done by Dr. Rochon-Duvigneaud and Prof. Ch. Maurain (La Nature, 1923, 232) in respect of homing pigeons. In this paper Dr. Rochon-Duvigneaud begins by stating the biological data, and Prof. Maurain, who is director of the Institute of Terrestrial Physics in Paris, follows with a discussion of the physical facts, particularly those of terrestrial magnetism, which might be relevant. Prof. Maurain confines himself to a statement of apparent possibilities; he holds none of them as proved, and he urges the need for experimental inquiry. Whether his tentative hypothesis is sufficiently plausible from a biological point of view to constitute a prima facie case for further research on these lines, however, is perhaps open to doubt.

Prof. Maurain's suggestion may be stated as follows : The magnetic declination (angle of magnetic needle's lateral deviation from the geographical meridian) and the magnetic dip or inclination (angle of needle's vertical deviation from the horizontal plane) both vary from place to place over the surface of the globe. The periodical variations at any given place, and the irregular disturbances which also occur, are small in proportion to the otherwise constant geographical differences. Roughly speaking, therefore, every locality has its characteristic declination and dip. If lines be drawn through the places having the same declination, and other lines through the places having the same dip, these lines are (in Europe) roughly at right angles to each other. The lines thus serve as co-ordinates, which fix the position of any given locality like lines of longitude and latitude. Moreover, the declination and dip increase or decrease progressively as distance from a given locality is increased, except along those lines where one or other factor remains constant. So much is a matter of common knowledge.

It has then to be supposed that the pigeons are sensitive to changes in declination and dip, and indeed simultaneously sensitive to each factor independently of the other, and that when removed to a new locality the birds have a natural tendency, so to speak, to seek their own magnetic level. If a pigeon be removed to another place having the same declination but a greater (or less) dip, it would fly along the line of equal declination in the direction of decreasing (or increasing) dip. Similarly, if removed to a place having the same dip, it would follow the direction in which the declination changes towards the amount found at the home locality.
Again, in the more general case of a bird removed to a place where both declination and dip are different, it would be affected by both factors and its homeward path would be the resultant of the two tendencies. (It is noted that there is no question of remembering the magnetic changes experienced on the outward journey, as a bird removed by a circuitous route will find a direct path home.)

Ornithologists will be grateful to the physicist for the statement of a possible case, but they will regret that Prof. Maurain has confined his argument to the relatively short journeys performed by homing pigeons and to the magnetic phenomena as they exist in Europe (for it is not in every part of the world that the lines of equal declination and of equal dip run at right angles to each other, and that there is only one point at which a given pair of values for these factors is to be found). They would have liked to see a case similarly stated in respect of the migrations of, say, swallows from South Africa to England (cf. NAture, March I6, I922, p. 346), over an area in which more complicated changes in terrestrial magnetism have to be reckoned with. Dr. Cathelin notwithstanding ("Le retour au nid reste donc pour nous une des grandes hérésies ornithologiques"), an ever-increasing volume of records of marked birds shows that swallows and others commonly perform very accurate feats of "homing" from great distances.

Returning to homing pigeons, however, we may examine the argument more closely. The physical phenomena exist, and a remarkable power of orientation is undoubtedly involved in homing; can a connexion be traced between them? The most serious objection seems to be the entire absence of any evidence of sensibility to magnetism on the part of birds or other animals; and without this physiological link speculation must needs be barren. Kelvin got negative results from his experiment of subjecting the human head to the influence of a powerful magnetic field; Du Bois observed no effect on protozoa; and the writers of the paper under discussion have similarly failed with pigeons. Within a limited field, it must be remembered, the strong electro-magnets used in such experiments are very many times more powerful than terrestrial magnetism: yet for Prof. Maurain's hypothesis we must suppose that birds are sensitive not only to minute changes in terrestrial magnetism, but also to changes in two of its factors separately. It does not seem, therefore, that the theory can be regarded as a promising one.

Prof. Maurain apparently holds, nevertheless, that there is a good case for further investigation, and he discusses in some detail the conditions necessary for an experiment on pigeons during their actual homing flight. It is not, of course, possible to interfere with terrestrial magnetism by means of artificial magnets over an area of any size, although it is admitted that pigeons find their way back as easily to lofts in great cities, where electric cables and the like cause an appreciable disturbance, as to lofts in the open country. The pigeon might be made to carry a small magnet and thus be kept within its field, but negative results would not be considered altogether convincing, because the amount of interference with terrestrial magnetism would be constant throughout; whether a portable apparatus giving varying magnetic effects could be designed is not discussed. Our author considers that

NO. 2795 , VOL. I 11$]$ 
the only possibility is to rear pigeons in a confined space within a powerful and varying magnetic field, and to remove them eventually to a distance under similar conditions. On being liberated for flight the birds would, for the first time in their lives, come under the undisturbed influence of terrestrial magnetism, and in these circumstances it should, by hypothesis, be useless to them as an aid to homing. We may hope that the experiment will be attempted, but until and unless some positive indications are obtained we are justified in remaining more than a little sceptical as to the existence of a "magnetic sense." $\quad$ A. L. T.

\section{New General Anæsthetics.}

$\mathrm{T}^{\mathrm{H}}$ HREE-QUARTERS of a century ago the era of surgical anæsthesia was suddenly and unexpectedly opened with ether, chloroform, and nitrous oxide. The relative importance of these three in surgery has varied at different times, but none of the many substitutes suggested has secured a permanent footing in surgery, although several have had a shorter or longer vogue.

The paramount consideration in the choice of an anæsthetic is safety, and it is recognised that this may be conduced to by avoiding the prolonged unconsciousness of ether and chloroform. This has led to the increased prominence of nitrous oxide in recent years; but while this induces rapid and safe anæsthesia, it can be used for ordinary surgical work only with difficulty, owing to the cumbrous apparatus necessary.

Within the last few weeks two new anæsthetics have made their appearance in acetylene and ethylene, each diluted with oxygen; the first hails from the pharmacological laboratory of Prof. Straub of Freiburg, the second from Drs. Luckhardt and Carter of the University of Chicago. Each is said to induce anæsthesia without preliminary discomfort and with rapid recovery afterwards. This short duration of the action is similar to that of nitrous oxide and ethyl chloride, and is associated with the rapid absorption and elimination of the anæsthetics owing to their volatility; for all four are gases at ordinary temperature and pressure.

The new anæsthetics appear to be more powerful than nitrous oxide, however, for they are efficient when mixed with oxygen, and the anæsthesia can therefore be maintained continuously without danger of asphyxia. On the other hand, they are devoid of the halogen component of ethyl chloride, which lends it an effect on the heart which is absent in the unsubstituted molecule. The introduction of these unsaturated hydrocarbons is of practical and also theoretical interest. A higher homologue of ethylene was early suggested by Snow (1853) as an anæsthetic in amylene, and more recently a purer preparation of analogous composition had some success under the name of pental. Ethylene and acetylene have to be kept under high pressure, and it may be that this inconvenience may militate against their more general use, even if the favourable reports given by their sponsors are confirmed by further experience.

\section{Obituary.}

Mrs. Ludwig Mond.

LL friends of Mrs. Mond, widow of Dr. Ludwig A Mond, will mourn her death, on May r6, at The Poplars, Avenue Road, Regent's Park, of which she had so long been the attractive figure and ornament.

Those who knew Dr. Mond intimately enough to visit his home could never think of him alone but necessarily associated him with his wife; they were an inseparable couple in thought and, in all their social interactions, as wonderfully adjusted as were the two salts he caused to interact in the great works his genius created. This came from the fact of their early intimate association.

They were first cousins; her mother was his loving counsellor when he was a youth; and they became secretly engaged before he was of age, when she was a girl of thirteen at school. Up to their marriage, after he was established in England, they maintained a constant correspondence, of a most intimate character, which it has been my privilege to see in large part; it affords the most striking picture possible of the charm and simplicity of German life in those early days. Mrs. Mond's letters from the beginning show an extraordinary maturity and sobriety of judgment. It is clear that Dr. Mond's later æsthetic development was greatly due to the foundation laid during this period, mainly through the influence his wife exerted on him. In their married life she cast a spell upon all his friends which greatly added to his influence. Her ability is well brought out by Mr. T. P. O'Connor, M.P., in the Sundav Times, in the following few lines:
"Mrs. Mond, his wife, struck me as being almost as big a mind as her husband. In a few sentences, describing the difierence between the Gothic and the Renaissance types of architecture-especially of the architecture of the cathedral-I got a clearer idea of the two ideals than I could have learned from a dozen books."

By Mrs. Mond's death, the nation comes into possession of Dr. Mond's great gift of Italian pictures and the Royal Society receives his bequest of $50,000 \mathrm{l}$. It is a sad fact that the enterprise in which Dr. Mond was so particularly interested - the International Catalogue of Scientific Literature-the promotion of which, I know, was specially in his thoughts when he made the bequest, has been allowed to lapse almost at the moment his gift becomes fruitful. He may be said to have been the main promoter of the Catalogue and the greatest believer in its ultimate value to the scientific worker. He would have deplored nothing more than its abandonment at the time when development of the spirit of international co-operation is so imperative a need.

Unfortunately, we have lost the broad outlook which characterised Mond and his generation; Michael Foster seems to have been its last exponent in the Royal Society, the last who dared to cultivate enthusiasm. Apparently, we are no longer able to maintain continuity of thought and action; nor, when we have done well, to realise the importance of our work and take pride in carrying it to completion. We prate of science but the true spirit of scientific method is no longer in us.
H. E. A. 